\title{
Alessandra Quarta* Narratives of the Digital Economy: How Platforms Are Challenging Consumer Law and Hierarchical Organization
}

https://doi.org/10.1515/gj-2020-0026

Abstract: Digital platforms are the essential infrastructures of electronic commerce, online communication, and digital social relationships. They connect two interdependent groups of web users (parties offering goods, services, and digital content; and parties interested in accessing this supply) and enable their transactions. Moreover, they provide additional services such as online payment, collection of reviews and feedback, and internal instant messaging. However, the term "platform" can be misleading, since it seems to denote a virtual space or a technical tool without legal personality. In other words, platforms are masking corporations who hide behind them in order to avoid the legal responsibilities stemming from their status as social institutions. This exploits the dominant theory of the firm as a nexus of contracts and is intended to release the agents involved in the system of production from the restrictions that protect weaker parties in the age of industrial capitalism. Companies who organize production through platforms thus obtain both indirect and direct benefits. In particular, indirect benefits derive from making consumer law more complicated to apply by creating conditions that frustrate the traditional distinction between professionals and consumers. In fact, any user can provide services and sell or share their personal goods (e.g., cars, apartments, clothes, etc.) and other commodities through platforms. However, this does not mean that information asymmetries do not continue to exist, or that weaker parties do not need to be protected. This confusion benefits companies that enable these transactions, since online relationships are not burdened by informative duties. In this case, companies use the platform narrative to facilitate peer-to-peer transactions, where simple, ubiquitous exchanges yield advantages. In addition, platforms provide direct benefits by eliminating the hierarchical organization of their production system in order to adopt the least burdensome and most flexible forms of employment. Companies generally rely on ICT tools to show that the parties offering the service are independent and are not subject to their control. The platform narrative glosses over the labor exploitation issues generally referred to as

*Corresponding author: Alessandra Quarta, Department of Law, Università di Torino, Turin, Italy, E-mail: alessandra.quarta@unito.it 
"uberification". In addressing the questions outlined in this introduction, the paper will be organized as follows. Part I will discuss how the platform economy is challenging consumer law by short-circuiting its legal grounds in ways that allow companies to benefit. Part II will focus on the direct effects of the platforms' denial of hierarchical organization: starting from the Italian Supreme Court's ruling in the Foodora lawsuit, we will explore emergent models for organizing the system of production and their impact on the main categories of private law.

Keywords: consumer law, digital market, platform economy, sharing economy

\section{Introduction}

Digital platforms are the essential infrastructures of electronic commerce, online communication, and digital social relationships. They connect two interdependent groups of web users (parties offering goods, services, and digital content; and parties interested in accessing this supply) and enable their transactions. Moreover, they provide additional services such as online payment, collection of reviews and feedback, and internal instant messaging.

However, the term "platform" can be misleading, since it seems to denote a virtual space or a technical tool without legal personality. In other words, platforms are masking corporations who hide behind them in order to avoid the legal responsibilities stemming from their status as social institutions. This exploits the dominant theory of the firm as a nexus of contracts and is intended to release the agents involved in the system of production from the restrictions that protect weaker parties in the age of industrial capitalism. Companies who organize production through platforms thus obtain both indirect and direct benefits.

In particular, indirect benefits derive from making consumer law more complicated to apply by creating conditions that frustrate the traditional distinction between professionals and consumers. In fact, any user can provide services and sell or share their personal goods (e.g., cars, apartments, clothes, etc.) and other commodities through platforms. However, this does not mean that information asymmetries do not continue to exist, or that weaker parties do not need to be protected. This confusion benefits companies that enable these transactions, since online relationships are not burdened by informative duties. In this case, companies use the platform narrative to facilitate peer-to-peer transactions, where simple, ubiquitous exchanges yield advantages.

In addition, platforms provide direct benefits by eliminating the hierarchical organization of their production system in order to adopt the least burdensome and 
most flexible forms of employment. Companies generally rely on ICT tools to show that the parties offering the service are independent and are not subject to their control. The platform narrative glosses over the labor exploitation issues generally referred to as "uberification".

In addressing the questions outlined in this introduction, the paper will be organized as follows. Part I will discuss how the platform economy is challenging consumer law by short-circuiting its legal grounds in ways that allow companies to benefit. Part II will focus on the direct effects of the platforms' denial of hierarchical organization: starting from the Italian Supreme Court's ruling in the Foodora lawsuit, we will explore emergent models for organizing the system of production and their impact on the main categories of private law.

\section{Part I: Vanishing Differences: How Platforms are Challenging Consumer Law}

\subsection{Consumer Law Protection Meets the Challenge of the Peer- to-peer Economy}

In digital markets, platforms intermediate transactions among users, ${ }^{1}$ and enable very different relationships. ${ }^{2}$ In this paper, we will focus on peer-to-peer businesses, where the negotiating parties are seen as equal subjects, since the line of distinction between professionals and consumers seems to be blurred.

To introduce this topic, one could think of eBay, a platform allowing users to sell new or second-hand goods. In these transactions, the party offering the goods is not necessarily a trader, and this means that consumer protection law cannot be applied even though the buyer meets the legal definition of consumer.

This is a very minor example, considering that second-hand markets are not new, although their global extension via the Internet is a true novelty. In the Web 2.0 era, the sale of goods is not the only economic operation that platforms permit: in recent years, many services traditionally provided by professionals have been run by natural persons with no entrepreneurial organization of any kind, thanks to the visibility and support (in terms of additional services) offered by digital platforms. The sharing economy provides many examples. Home-sharing sites enable owners of apartments or single rooms to offer accommodation to tourists for short

1 The rise of digital platforms is described by Srnicek (2017).

2 Companies use platforms to organize inputs for providing intermediation, which is one of the information society services contemplated by Directive 2000/31/EC. 
periods (Airbnb); transportation within the city is provided by non-professional drivers with their own cars (Uber); meals are prepared by non-professional chefs in their own homes (Gnammo); and household tasks are carried out by people exchanging their own skills and time (time banks).

In this scenario, peer-to-peer transactions are regulated by two different contracts.

First, all users enter into a contract with the platform, by agreeing to its terms of use. Generally, platforms' terms of use do not differ according to what the user intends to do: in other words, since all users can offer goods, services and digital content, as well as buy them, no distinction is possible.

Second, the party offering goods, services or digital content (leasing an apartment, giving a ride, cooking, etc., which we can call generically "underlying services") enters into a contract with another platform user who is interested in purchasing them. Defining the type of the agreement is often an easy interpretative task, since these economic transactions generally do not have features that differ from those of their non-platform counterparts. In fact, providing accommodation for short periods is a short-term rental, and similarly, transportation does not require an alternative legal framework.

By contrast, ensuring the consumer rights contemplated by EU consumer protection law is a complex issue, since the factors whereby that set of rules is ordinarily applied are vanishing in peer-to-peer transactions (Smorto 2008).

In fact, the protections and remedies under consumer protection law relate only to business-to-consumer relationships (B2C), where information asymmetries make the consumer the weaker party of the contract and justify the introduction of special systems of protection. When the relationship is not affected by information asymmetries, the parties are taken to be equal in the bargain, according to the liberal foundations of contract law (Collins 2008). Thus, in this case no special set of rights is applied and transactions are regulated by general contract law as defined in civil codes.

In this scenario, platforms take advantage of the creation of new agents in the market, who are generally referred to as "prosumers". Combining the roles of producer and consumer, these hybrid figures can at the same time be parties offering goods, services, and digital content, and parties interested in purchasing them. These dual roles and the ease of shuttling between them derive from the fact that providing services does not necessarily require an entrepreneurial organization.

As mentioned earlier, personal goods are generally used to run platform-based businesses (Nemeth and Morais Carvalho 2019). To simplify, ownership of underused assets (a second apartment or vacant rooms) and an Internet connection are the two necessary and sufficient assets for organizing an accommodation service 
through Airbnb. The "host" is not a professional, since he or she is not acting within a scope of trade, craft, or business; consequently, consumer protection law does not regulate his/her relationship with the "guest": withdrawals, for instance, are not governed by Directive 2011/83/EU, Article 9; and the Brussels Convention does not apply.

However, legal scholars, national lawmakers, and city councils are wondering whether objective standards can be defined to distinguish self-organized activities from professional businesses (Busch 2019, p. 41; Morais Carvalho and Policarpo 2018; Nemeth and Scharmer 2016). This would make it possible to apply administrative provisions, such as those requiring a license to run the activity, as well as tax regulations. This approach would also impact the application of consumer protection law by influencing the legal qualification of parties offering goods, services and digital content, and enabling a professional to be identified in the transaction.

It should be noted that renting an apartment for a few days per year is undoubtedly different from doing so for long periods, because an organizational effort is required: the question is how many days or months should pass before an "occasional performance" becomes an established and professional service? These key features of the platform economy challenge the digital single market, since EU Member States give different answers to this question.

\subsection{Dual-Purpose Transactions in Consumer Law: Interpretative Standards and Missing Factors}

If we look at these issues through the lens of consumer law, there is a problem of legal qualification concerning the notion of professional and its potential extension through interpretation.

In particular, the legal qualification of parties offering goods, services, and digital content requires that the party's purpose be defined, whereas distinguishing between personal and professional purposes can be complicated. In the past, a similar problem arose regarding consumption, and those situations in which consumers enter into a contract with a professional to pursue a personal purpose, where private and professional interests are mixed. Self-employed professionals may enter into mixed transactions when buying goods or services that can be put to a dual use, as for instance occurs when a lawyer purchases a computer used both for writing legal opinions and sending private email.

The EU Directives concerning the harmonization of national consumer protection law define the notion of consumer very differently. Nevertheless, they share a common core, in that the consumer is defined in negative terms: viz., a consumer 
normally acts for purposes outside those of an economic activity such as a trade, craft or business listed in the definition of a professional. Clearly, then, mixed transactions-i.e., those pursuing a dual purpose-are controversial. The EUCJ has addressed how they should be qualified in two important lawsuits.

In the first, the case concerned a contract concluded by a natural person outside the scope of a professional activity (Case C-45/1996) viz., a guarantee for repaying a debt contracted by a third person who was acting for a professional purpose. The Court ruled that the guarantor must be qualified as a consumer, since he signed the contract to pursue a personal purpose by negotiating with the bank. Thus, the fact that the beneficiary was a professional did not change the nature of this business-to-consumer transaction.

This first decision is less interesting than the second one that we will analyze, since it did not deal with a true mixed transaction: the guarantee agreement involved a professional (a bank) and a consumer. The nature of the third party (the recipient) is not relevant, even if this kind of contract seems to force the doctrine of privity, as the guarantee agreement involves specific obligations and rights for the parties entering into it.

As anticipated, the second case to be analyzed penetrates more deeply into the problem. In the Gruber case (Case C-464/2001), the plaintiff was a farmer who owned several buildings, used in part for his business, and in part as dwellings. To replace the roof tiles on his buildings, he bought tiles from an Austrian company (the defendant), but after the materials were delivered, Mr. Gruber discovered significant defects that obliged him to re-tile the roof. For this reason, he brought suit against the company together with a claim for damages, "seeking reimbursement of the costs of the tiles and of the expense of removing them and retiling the roof". However, whether consumer protections applied (in this case, the Brussels Convention and special rules of jurisdiction) depended on whether the plaintiff could be considered a consumer, since the purpose for which he bought the tiles had been partially professional-tiling the roof of the farm building-and partially personal-tiling the roof of his dwelling.

The Court ruled that "a person who concludes a contract for goods intended for purposes which are in part within and in part outside his trade or profession" may not rely on the special rules introduced for protecting consumers "unless the trade or professional purpose is so limited as to be negligible in the overall context of the supply, the fact that the private element is predominant being irrelevant in that respect". The principle is quite restrictive, and to ensure its consistency, the Court ruled that in mixed transactions, consumer law cannot be applied if the person negligently creates the impression that he or she is acting for a professional purpose. National courts shall evaluate factual elements and the 
concrete events to determine if the professional purpose has been limited, and thus negligible.

The question thus arises as to whether this approach can be applied in peer-topeer transactions, where the party purchasing goods, services or digital content invokes consumer protection law. In particular, the point is how the professional purpose should be scrutinized, since in these cases, the business's legal form is not an indicator. Even if this scrutiny should be based on a case-to-case approach, identifying a set of general criteria can support national courts. For this reason, it is interesting to analyze the factors and conditions used by the European Court of Justice to identify professionals in peer-to-peer transactions in its recent ruling in case C-105/17 in October 2018 (Case C-105/2017).

The case concerned the interpretation of Article 2(b) and (d) of Directive 2005/29/EC concerning unfair business-to-consumer commercial practices, according to the request made in the proceedings between Ms. Evelina Kamenova and the Bulgarian Consumer Protection Commission (CPC). In particular, this national authority had imposed administrative fines on Ms. Kamenova, arguing that she failed to provide information to consumers in advertisements for the sale of goods published on a website. In fact, she had advertised the sale of a watch and other goods, not providing the information required by the national law implementing Directive 2005/29/EC. ${ }^{3}$ The CPC qualified this lack of information as an unfair commercial practice, assuming that Ms. Kamenova as a professional trader had to respect informative duties; this qualification was based on the consideration that even though she was a natural person, she had published eight advertisements on the website offering eight different new and secondhand items.

The request for a preliminary ruling required that the EUCJ examine whether Ms. Kamenova could be considered a professional trader and as a consequence, if her online activities could be considered as commercial activities.

For this purpose, the judges introduced a set of criteria stated by the Advocate General in his opinion. He argued that national courts "have to verify whether the sale on the online platform was carried out in an organized manner, whether that sale was intended to generate profit, whether the seller had technical information and expertise relating to the products which she offered for sale which the consumer did not necessarily have, with the result that she was placed

3 Specifically, "the trader's name, postal address and email address, the total price of the product put on sale, inclusive of taxes and fees, the payment conditions, the conditions of delivery and performance, the consumer's right to withdraw from the distance contract, the conditions, period and procedures for exercising this right as well as a reminder that there was a statutory guarantee that the goods sold would be in conformity with the sales contract”. 
in a more advantageous position than the consumer, whether the seller had a legal status which enabled her to engage in commercial activities and to what extent the online sale was connected to the seller's commercial or professional activity, whether the seller was subject to VAT, whether the seller, acting on behalf of a particular trader or on her own behalf or through another person acting in her name and on her behalf, received remuneration or an incentive; whether the seller purchased new or second-hand goods in order to resell them, thus making that a regular, frequent and/or simultaneous activity in comparison with her usual commercial or business activity, whether the goods for sale were all of the same type or of the same value, and, in particular, whether the offer was concentrated on a small number of goods". According to the Court, however, these criteria "are neither exhaustive nor exclusive, with the result that, in principle, compliance with one or more of those criteria does not, in itself, establish the classification to be used in relation to an online seller with regard to the concept of 'trader'”.

Indeed, "in the light of all relevant circumstances of the individual case" and despite the fact that "the sale [was] intended to generate profit" and the simultaneous presence of "a number of advertisements offering new and second-hand goods for sale”, Ms. Kamenova could not be qualified as a professional seller, and accordingly did not engage in unfair commercial practices.

The set of criteria provided by the EUCJ is quite broad, and can facilitate the interpretative tasks of national courts. However, the most interesting point in this decision concerns the functional approach adopted by the Court to determine who qualifies as a professional: standards and criteria for applying this category should be always connected with the essential rationale of consumer protection law, which assumes that "the consumer is in a weaker position, in that he must be deemed to be less informed, economically weaker and legally less experienced than the other party to the contract".

Nevertheless, defining criteria and standards can create uncertainty in the EU digital single market, especially if national courts acting in their own judicial autonomy decide to assign greater weigh to some factual conditions than to others. It seems to be one of those situations in which uniformity among national regulations could benefit the consumer, who should be protected throughout Europe's digital single market.

While we wait to see what action will be taken in this area, two European Commission Communications have provided some interesting (if contradictory) signals. 


\subsection{EU Integrative Standards}

The European Commission analyzed such problems in Communication

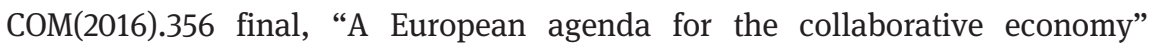
(Cauffman 2016), where it proposed a list of factors which in combination suggest that a party acting as a service provider could be considered as a professional in peer-to-peer transactions.

The first factor is the "frequency of the service". This factor is very broadly defined, leaving national authorities to set specific thresholds for determining whether services are provided on an "occasional basis", i.e., a "purely marginal and accessory basis" rather than regularly.

The second factor is the "profit-seeking motive", which could be deemed to exist when parties offering the service obtain remuneration beyond cost compensation. Thresholds can be introduced for this factor and avoid the indeterminacy of "cost compensation", especially in those cases in which determining the costs incurred is difficult or may be arbitrary.

The last factor is the level of turnover: according to the European Commission, "the higher the turnover generated by the service provider (be it from one or several collaborative platforms), the greater the indication that the provider may qualify as a trader”. To assess turnover, data from multiple platforms should be cross-checked, since the same activity can be provided through different platforms.

When the combination of these factors suggests that the party offering a service is a professional, consumer protection law should be applied. Nevertheless, the most interesting consequence concerns the application of administrative standards and regulations to the provision of the underlying service, such as licensing and authorization obligations.

It should be noted that the European Commission has gradually abandoned the approach that inspired this Communication. In 2016, the unexpected rise of the sharing economy, and the Uber effects in particular, pushed the EC to focus on the collaborative economy as an original phenomenon. Nevertheless, the EC's most recent documents have adopted a broader perspective on the platform economy, given the need to establish new rules and protections for weaker parties in the digital market. According to this mission, special rules governing the relationships between professional service providers and the platform (a typical business-tobusiness transaction) have been introduced to protect providers and their economic activity from the platform, which may exercise arbitrary power, e.g., by deleting private accounts (Iamiceli 2019). 
This is the approach behind the European Commission's 2018 Communication entitled “A New Deal for Consumers” and Directive 2019/2161/EU.

In the first document, the Commission identified a transparency issue: " $[t]$ oday, when consumers visit an online marketplace, they do not always know from whom they are buying (from a professional trader or another consumer). Many consumers are under the impression that they are buying from the online marketplace and are thus entering into a contract with that platform. In reality, they may most often be buying from a third-party supplier listed on the online marketplace. As a result, consumers may falsely think they are dealing with a professional trader (hence benefitting from consumer rights). This confusion can cause problems if something goes wrong with an online purchase, because it is not always easy to establish who is responsible for any faults. This diminishes the possibility of obtaining a remedy".

Starting from this analysis, Directive 2019/2161/EU amended Directive 2011/ 83/EU by adding Article 6a establishing a new obligation on "the provider of the marketplace" (the digital platform) to inform users "whether the third party offering the goods, services or digital content is a trader or not". This information is provided "on the basis of the declaration of that third party to the provider of the online marketplace". Moreover, when the party offering the goods, services or digital content is not a trader, the platform shall inform the user that consumer protection law does not regulate the transaction.

It should be pointed out that the Directive allows Member states to impose additional information requirements, recognizing the need to protect consumers by imposing new obligations on platforms.

Though this political choice is laudable inasmuch as the platform is best able to fulfill these obligations, the provision has several shortcomings.

First, the platform informs users whether the third party offering goods, services, or digital content is a trader on the basis of the latter's declaration, but there is no way of assessing its truthfulness. Second, Article 6a totally avoids addressing the conditions that make the party offering goods, services or digital content a professional, preferring to tackle the need for protection by introducing a new information duty. This technique is particularly common in the regulation of digital markets and electronic commerce, but is probably insufficient to ensure uniform protection in connection with the problems discussed above. Currently, parties offering goods, services and digital contents can thus be considered as professionals in some European member states but not in others. As a consequence, consumer protection law is applied in very different ways, and this undermines all the effort that has gone into building a single digital market. 


\section{Part II: Objecting to Hierarchy. How Platforms are Challenging the System of Production and Labor Law}

\subsection{The Provision of the Underlying Service}

In the digital market, parties offering services can operate independently, using platforms to obtain intermediation and find potential customers. In some cases, however, they are not so independent in providing the underlying service, since platforms seem to exert a control over them, breaking the screen and intervening in offline transactions. The problem is that in these cases, the company does not formalize this relationship in a labor contract. Thus, the question is whether parties offering the service are running the business on behalf and in the interest of the company, which is not limiting its own activity to providing the information society services through the platform. Moreover, there are situations in which the platform is expressly engaged in the provision of the underlying service, but the parties who materially perform it are not hired by the platforms as employees.

Thus, the first problem to be dealt with in interpreting the situation consists of identifying standards and criteria for understanding whether the parties offering services are acting on behalf and in the interest of the platform. In this case, such an assessment is necessary in order to apply labor and social protection, since "the risk is that these activities are not even recognized as work” (De Stefano 2014).

A common starting point in discussing this issue is the relationship between Uber and its non-professional drivers, ${ }^{4}$ whose qualification has been argued before a number of judges in Europe-at the Employment Tribunal of London, for example-and in the United States. ${ }^{5}$ In these judicial proceedings, courts have considered non-professional drivers using Uber software to be employees of the platform, since they are completely controlled by the latter in providing the transportation service. Thus, Uber is neither a company providing ICT solutions, and in particular a specific software program, nor a market-a neutral and virtual space where drivers and passengers meet; on the contrary, the courts have found

4 This platform enables non-professional drivers to transport passengers over short routes. The user can send a request with the route to be covered, and the driver receives a notification with the user's position, thanks to GPS service. Non-professional drivers must abide by Uber's requirements to provide the service, but they do not need a licence or an authorization.

5 For a comparative study see Recchia, "Gig Work and the Qualification Dilemma: From the Judicial to the Theoretical Approach”, in Wratny, Ludera-Ruszel (2020), p. $141 \mathrm{ff}$. 
that Uber is to be considered a transportation company and accordingly, drivers are its employees.

Although national courts are taking the problematic nature of Uber relationships into consideration, the EU has not been particularly proactive in defining standards for determining when parties are providing services on behalf and in the interest of the platforms. As mentioned earlier, some interesting suggestions are included in Communication $\operatorname{COM(2016)~} 356$ final, where the Commission listed three criteria that can be useful in understanding whether if the platform is providing the underlying service rather than limiting itself to providing information society services.

Here, the approach is completely different from that taken by the courts: the European Commission did not wish to list criteria for distinguishing between independent providers and dependent workers, but only to identify conditions under which the provisions of Directive 2000/31/CE are not applicable, and in particular, the special rules it establishes for internet service providers' liability (Articles 13-16). According to the Commission, the platform provides the underlying service when it exerts a significant level of control or influence over the party offering the service, as indicated by: (1) the price, when it is set by the platform and the party offering the service has no ability to change or adapt it; (2) key contractual terms, when the platform determines "the contractual relationship between the underlying services provider and the user (such as for example setting mandatory instructions for the provision of the underlying service, including any obligation to provide the service)"; (3) ownership of key assets: to be responsible for the provision of the underlying service, the platform must be the owner of the assets needed to carry out the activity. The Communication established that "[w]hen these three criteria are all met, there are strong indications that the collaborative platform exercises significant influence or control over the provider of the underlying service, which may in turn indicate that it should be considered as also providing the underlying service (in addition to an information society service)".

Even if the overall standard the Commission proposed in the Agenda is a caseby-case approach, the document is not sufficient to deal with the problem described at the beginning of this paragraph. In fact, the Commission does not focus on qualifying the relationship between platform and party offering the underlying service; in addition, the criteria do not work in concrete situations. In sharing economy transactions, parties offer services by using their own assets. Consequently, the third standard can never be applied and all three criteria will not be met.

Similarly, the EUCJ's ruling in the Uber Spain case does not resolve our doubts (Case C-434/2015). The dispute brought before the EUCJ stemmed from proceedings in Spain, where the professional taxi drivers' association Élite Taxi 
brought an action seeking a declaration about Uber's unfair competition practices, resulting from the benefit that the platform obtains by not complying with administrative law and its requirements. The EUCJ found that Uber exercised decisive control over the non-professional drivers: in fact, the platform selected them on the basis of special requirements; sets the final fare; and receives the amount of this fare from the client through its online payment service before paying part of this amount to the driver. Moreover, the app provided by Uber to enable digital transactions is essential to creating a market for these types of service. This means that without the Uber app, that market would not exist. For these reasons, Uber's main activity is not intermediation, but transportation that is materially performed by non-professional drivers that the company controls decisively. ${ }^{6}$

Determining whether a labor relationship exists hinges on identifying control and influence: this analysis is complicated by many factors that are the unexpected results of technology. However, this discussion does not concern only the legal qualification of the platform as employer and parties offering the services as employees. In general, it also opens a new debate over the post-industrial transformation of the firm, considering in particular digital platforms' attempt to escape from this qualification as a strategy for avoiding the main legal effects normally associated with this institution. Our discussion of this argument will start from the Italian Supreme Court's decision in the Foodora case.

\subsection{The Foodora Case}

Foodora was a digital food delivery platform. Though the company has now been wound up, there are many similar examples (Glovo, Uber Eats, etc.).

Foodora is a very good example of the platform economy, as it runs a business essentially based upon intermediation and cost reduction. On the one hand,

6 Recently, the EUCJ has consistently followed these criteria to decide if Airbnb is engaging in unfair competition. According to the judges, Airbnb's hosts are free to fix the accommodation's price, since the platform only supports them by suggesting the average rental generally applied in the neighborhood concerned. Moreover, as intermediation is the main service, Airbnb is not providing users with accommodation, but only with the information society service. We could question this perspective, arguing that Airbnb activities should not be compared to hotels or hostels, but with real estate agencies, which in many EU Member States are required to obtain a specific administrative licence to operate in the market. If intermediation in the real estate sector is Airbnb's main economic activity, there is thus no reason not to apply ordinary requirements and conditions simply because it is a digital platform, and not a traditional company. See C-390/2018 Airbnb Ireland, Judgement of 19 December 2019, in curia.europa.eu. 
Foodora utilizes application software that puts parties ordering food in contact with restaurants offering home delivery. In this sense, Foodora is a typical multiside platform, which leverages the advantages of connecting two separate sides of the market. On the other hand, Foodora differs from Airbnb and Uber because it is directly involved in home delivery, engaging riders-cyclists pedaling their bicycle to deliver-as independent contractors who collect food from restaurants and deliver it to customers. Shifts and orders are established and communicated through an app managed by the company, and for this reason, riders are engaged in "work-on-demand via app" (De Stefano 2014, p. 472). In this case, the main problem concerns how riders' relationship should be qualified in the framework of labor law. In fact, since Foodora exercises a significant amount of control over the riders, qualifying them as independent contractors can be a way of avoiding the labor and social protections generally afforded to employees.

This was the conflict decided by the Italian Supreme Court in 2019. ${ }^{7}$ The riders demanded the application of Article 2, Legislative Decree 81/2015, whereby certain rules applying to employees can be extended to those who meet the criteria identified by the law. The company rejected this interpretation, arguing that no similarities with an employment relationship exist. The reasons Foodora provided in support of this argument are very interesting for our inquiry.

According to the company, the riders' position should be defined taking into account the elements of time and space (Cruz Villalón 2018). With regard to the first, Foodora explained that the riders were fully independent in choosing when to work: each week, they received a shift plan consisting of different time slots to be covered; they were free to select the slot through the app they were required to install on their own smartphones, and they could also decide not to express any preference. Similarly, with regard to space, riders were free to choose among three different places in the city, where they would start their shifts and wait to be contacted by restaurants.

The company claimed that the ability to select shifts and locations indicated that riders were independent, and that the company did not exercise hierarchical control: for this reason, Foodora argued that the riders cannot benefit from the rights and protections normally applying to employees.

This argument was rejected by the Italian Supreme Court, who took an alternative view of both "time" and "space" in the relationship between Foodora and the riders. According to the Italian judges, riders exercise their independence until the beginning of the shift, after which they are controlled by the company. The same argument applies to the choice of place, which occurs before the beginning of the shift during which riders must execute the platform's orders. In fact, Foodora

7 Italian Supreme Court, January 20, 2020. 
instructs the riders to reach the restaurant and then provides the address of the party ordering food. The riders are paid for their working hours, but this hinges on their being able to confirm delivery, and they are penalized if delivery is not completed within $30 \mathrm{~min}$ of the moment they take food from the restaurant. In support of the Court's arguments, moreover, we can add that the riders' independence is also refuted by the fact that Foodora can dismiss riders for any or no reason simply by disabling their account for using the application software.

It should be noted that Foodora's arguments about time and space are intended to reject two very traditional features of the industrial firm: shifts are established hierarchically by the employer, as is the place were activities are to be carried out.

The core of this discourse is the denial of hierarchy and the attempt to demonstrate riders' independence; Foodora sought to show that its organization is heterarchical and decentralized, enhanced by its technological infrastructure. We will now consider this argument, in order to investigate whether platforms such as Foodora have in fact abandoned the traditional paradigm of the firm, and break the institution versus market dichotomy by using technologies.

Accordingly, the following paragraphs will clarify the expression "heterarchical organization", thus enabling us to compare the Foodora system of production with organizations such as Linux or Wikipedia.

\subsection{Heterarchy versus Hierarchy: Technologies and the Organization of the Firm}

In recent years, the debate over systems of production has been enriched by the introduction of an alternative to hierarchical structures.

Traditionally, the nature of the firm has been at the heart of this analysis, which seeks to clarify the justifications for preferring either property rights or contracts as the legal tools for regulating transactions in the market. In other words, agents involved in systems of production decide between two main models that are generally summarized through the dichotomy "make or buy".

Ronald Coase's seminal article "The Nature of the Firm” (Coase 1937; see also Coase 1960) continues to be one of the most influential explanations of this dilemma. According to Coase, firms are clusters of resources and agents (Benkler 2002, p. 372) organized for making products. Thus, they acquire raw materials and assemble them within the same structure. To achieve this result, firms are essentially based on both the centralization of relationships and the concentration of decision-making power in the hands of the entrepreneur. This solution is particularly efficient when transaction costs of the "buy" alternative, which consists of 
relying on markets and entering into contracts for assembling raw materials, are too high, so that concentration allows agents to save money.

The signals through which resources and agents are coordinated for production are instructions and orders given by the entrepreneur: for this reason, according to Coase's analysis, the essential legal core of the firm is the relationship between master-the entrepreneur-and servants (Coase 1937, p. 403), workers who execute orders and guarantee production. This relationship is regulated by labor contracts.

The firm's hierarchical nature is clear from this very traditional description. It results from the concentration of powers and relations, as well as from the centrality that property rights have in this institution. Similarly, the master-servant relationship completes this picture, introducing the power of the owner in a managerial command-based system.

In the last few years, however, a paradigm shift in the software industry has challenged this way of explaining production as based only on the make or buy alternatives, the hierarchical firm or the distributed system of contracts.

In fact, free software projects "do not rely either on markets or on managerial hierarchies to organize production” (Benkler 2002, p. 372): programmers contribute to their development even if they do not execute orders and do not receive a salary for their work; similarly, price does not direct their actions. In other words, we can say that the production of free software does not need the signals generated by the market (the system of prices), or the centralization typical of the firm which entails a command-based model represented by labor contracts.

Yochai Benkler has explained the role of cooperation and large-scale collaborations in many information production fields, using the software industry as a vantage point. Benkler shows that the production of culture and information (intangible goods that are commons) is possible and efficient even if it is not driven by market prices or managerial hierarchies: this model is called "commons-based peer production", and has emerged because the cost of organizing it is lower than that of using market or hierarchical organization. ${ }^{8}$

This model works efficiently when the object of production is information, since its non-rival nature facilitates decentralization, and the physical capital costs of production are not prohibitive, because of "the introduction of cheap-processorbased computer networks". Moreover, the production of information basically calls for creative talent, a type of input that is highly variable, "more so than traditional labor". A look at how Linux works will help us understand this system. This open source software is created and updated through the contributions of different programmers (the peers) who use their own computers to add or modify

8 Ivi, p. 403. 
content; similarly, the quality of this work is ensured by the community of users as a whole (a sort of peer-to-peer assessment).

According to Benkler, the evolution of technology and communication systems has laid the essential groundwork for the production of free and open source software: orders and prices are not needed in order to have an efficient system.

We might wonder whether the production of data and information has something in common with how companies organized as digital platforms operate. Considering this question can help us understand why a company can decide to run a business with this organizational model, as well as to identify the main signals that govern the system of production.

First, we must clarify what digital platforms are producing. To give a first general answer, we could say that they produce services. However, this response is not sufficient, because we must also define what kind of services they provide. The consideration presented in the first part of this paper can help us here: platforms provide users with an information society service, i.e., intermediation, and in some cases with the underlying service as well. This is the case for both Uber and Foodora, who use ICT tools to provide both types of service. In fact, they use an application software to connect users interested in the underlying service (transportation or home delivery), which employs algorithms to organize and control drivers and riders.

The extensive use of technology is probably the main argument that allows digital platforms such as Uber and Foodora to deny that they have a hierarchical structure. Thus, Foodora claimed in the Italian lawsuit that riders can decide independently when and where they work, and on closer inspection, this is possible thanks to the application software that the company provides to riders. As riders are required to download the app and install it in their smartphone, it is clear that the ubiquity and low cost of these tools facilitates the organization of production via a platform.

Production through platforms and the commons-based peer production described by Benkler have several features in common. Both are based on the extensive use of technology; both require that ownership of digital devices be widespread; and the tasks involved in production are quite small (and in fact, we normally speak of the "gig economy").

However, the main characteristic of commons-based peer production is the complete lack of a central authority who imparts instructions. In addition, it is not necessary to rely on prices to produce inputs, since programmers are driven by a very special set of personal motivations.

Here, we will focus only on the first characteristic - the presence or the lack of a central authority-since assessing the second in the gig economy would require a sociological analysis we are unable to pursue. However, we can state that riders work for an income, and they are often people in need who have found no other opportunities, as the large percentage of migrants among them demonstrates. 
It cannot be said that Foodora's production shows a lack of coordination, since the company schedules shifts in such a way as to provide restaurants with a sufficient fleet of riders: the company avoids "market dynamics that might lead to redundancy or wasted times and resources” (Tomassetti 2016). Moreover, Foodora uses standard contracts for hiring riders, and adopts systems to evaluate their performances.

Technology is a means of achieving these results, which are connected with the traditional exercise of the power of control. For this reason, it cannot shield the company from the application of state laws.

From this perspective, Foodora seems to match Coase's model of the firm, as it features hierarchy, control, and master-servant relationships. The company attempts to deny that it has such a structure by focusing on riders' independence as ensured by technology and algorithms.

Nevertheless, this distinction allows us to understand the rise of platforms as authentic alternatives to both the firm and the market, even if this theoretical approach must always be verified through a case-by-case approach.

We should assume that in the post-industrial economy, the main business consists in exploiting communications among Internet users: for this reason, intermediation is becoming the most important information society service. Thus, companies who want to operate such a business must be organized to produce inputs for accumulating human interactions.

In the digital setting, platforms are more effective in reaching this objective than firms and the market because they (1) create a limited digital area for users' interactions; (2) reduce the transaction costs of putting users into contact.

In fact, platforms are basically websites, tools for thematic communication, which can connect different types of users who share the same interest or the same need. Websites' design and legal infrastructure - their terms of use, in particularare intended to make them easy to use, to build trust in order to increase the number of users and thus take advantage of network effects. In this sense, providing intermediation through a platform will be possible as long as the transaction costs of finding parties, of facilitating the transaction, and of ensuring safety and quality ${ }^{9}$ are lower than those incurred in organizing these performances within a hierarchical structure or buying inputs on the market.

\footnotetext{
9 According to Munger, these are the main transaction costs that organizing through platforms cuts: "Provide information about options and prices in a way that is searchable, sortable and immediate; Outsource trust to assure safety and quality in a way that requires no investigation or effort by the users; Consummate the transaction in a way that is reliable, immediate and does not require negotiation or enforcement on the part of the users". M. Munger, “Coase and the Sharing Economy”, in Veljanovski (ed.) (2015), p. 201.
} 
When these conditions are met, platforms carry the theory of the "nexus of contracts" (Jensen and Meckling 1976)-which holds that firms are the result of the intersection of several transactions - to the extreme. In the neoliberal age, viewing the firm as a nexus of contracts has been hegemonic, bringing about a "paradigm shift from the institutional vision developed in Europe from the early twentieth century", in order to "produce even stronger disengagement of the firm from responsibility toward its own stakeholders such as workers" (Mattei and Quarta 2018, p. 75). Platforms have a light and flexible structure, and outsource the entire system of production with the exception of marketing and digital development. Production is carried out by users who interact on the website, companies have no responsibility because they are only intermediary agents, and entrepreneurial risks are reduced.

When companies decide to break the screen and provide the underlying service as well, production of the service can be divided into small components which can be assigned to temporary workers, making long-term contracts unnecessary. As we have demonstrated in the case of Foodora, this organizational approach cannot avoid providing rights and protections if the party offering the underlying service is under the platform's control. In other words, as defined in the legal framework, organizing production through a platform cannot shield the company from having to apply the sets of rules established for protecting the weakest parties.

\section{Conclusions}

In Parts I and II of this paper, we demonstrated that digital platforms are creating short-circuits in contemporary legal frameworks. In Part I, we discussed how digital platforms are disabling consumer law, while Part II was devoted to analyzing the relationship between the organization of the system of production and workers' protections.

In general, the issues we have examined demonstrate that corporations as social institutions are disappearing.

In fact, the narrative of the platform acts as a shield that provides companies with indirect or direct benefits. Among indirect benefits, the peer-to-peer approach, which does not assign specific roles as traders or consumers to the parties, facilitates transactions because there is no obligation to provide information. Companies benefit from the increase in interactions, and though they accumulate wealth, they do not contribute to ensuring a system of guarantees. In this sense, the duty introduced by the European Commission with Directive 2019/ 2161/EU is a faint attempt to rebalance the relationships. 
As for the direct benefits of organizing production through platforms and ICT tools, companies can reduce entrepreneurial risks, free themselves of responsibilities, and hire temporary workers. This has recently been confirmed during the Covid-19 emergency: the digital platform Glovo refused to provide its riders with personal protective equipment, claiming that they are self-employed contractors, and for this reason was ruled against by the Employment Tribunal of Florence. $^{10}$

In the general public debate, however, the effects of the platform narrative are even broader: consider, for instance, that in neglecting all discussion of the platforms' environmental impact, we have abandoned one of the major concerns of the liberal age.

In this grim scenario, it should be noted that courts often break down the narratives of digital platforms by applying a case-by-case approach, showing that the companies' claim to represent a paradigm shift is merely a self-serving means of dismantling systems of protection. More than a paradigm shift, we are dealing here with a paradigm slip (Kar and Radin 2018), whose purpose is to reduce the application of remedies and guarantees: the Foodora lawsuit demonstrates that new theoretical tools are needed for an informed discussion of how post-industrial systems of production can be reconciled with social guarantees, rights and the protection of the individual.

\section{References}

Benkler, Y. 2002. “Coase's Penguin, or, Linux and the Nature of the Firm.” Yale Law Journal 112: 1-73.

Busch, C. 2019. "Regulating Airbnb in Germany - Status Quo and Future Trends.” Journal of European Consumer and Market Law 1: 39-41.

Case. C-45/1996. Bayerische Hypotheken- und Wechselbank AG c. Edgar Dietzinger, in curia. europa.eu.

Case. C-464/2001. Johann Gruber c. Bay Wa AG, Judgement of 20 January 2005, in curia.europa.eu.

Case. C-434/2015. Asociación Profesional Élite Taxi c. Uber Systems Spain SL, Judgement of 20 December 2017, in curia.europa.eu.

Case. C-105/2017. Komisia za zashtita na potrebitelite contro Evelina Kamenova, Judgement of 4 October 2018, in curia.europa.eu; see also 19(6) Computer Law Review International, pp. 192-194.

Cauffman, C., 2016. "The Commission's European Agenda for the Collaborative Economy - (Too) Platform and Service Provider Friendly?.” Journal of European Consumer and Market Law 6, 235-43.

Coase, R. H. 1937. “The Nature of the Firm.” Economica 4: 386-405.

10 Employment Tribunal of Florence, April 1, 2020. 
Coase, R. H. 1960. "The Problem of Social Cost." The Journal of Law and Economics 3: 1-44.

Collins, H. 2008. The Law of Contract. Cambridge: Cambridge University Press.

Cruz Villalón, J. 2018. Le trasformazioni delle relazioni industriali di fronte alla digitalizzazione dell'economia. Giornale di diritto del lavoro e delle relazioni industriali 158, 463-92.

De Stefano, V. 2014. The Rise of the "Just-in-Time Workforce": On-Demand Work, Crowdwork, and Labor Protection in the "Gig-Economy". Comparative Labor Law \& Policy Journal 37, 471-504.

Jensen, M. C., and W. H. Meckling. 1976. "Theory of the Firm: Managerial Behavior, Agency Costs and Ownership Structure." Journal of Financial Economics 3, 305-60.

Kar, R. B., and M. Radin. 2018. "Pseudo-Contract \& Shared Meaning Analysis." Harvard Law Review 132, 1135-219.

lamiceli, P. 2019. "Online Platforms and the Digital Turn in EU Contract Law: Unfair Practices, Transparency and the (Pierced) Veil of Digital Immunity." ERCL 15 (4): 392-420.

Mattei, U., and A. Quarta. 2018. The Turning Point in Private Law. Ecology, Technology and the Commons. Cheltenham: Edward Elgar.

Morais Carvalho, J., and P. Policarpo. 2018. "Regulating Airbnb in Portugal.” Journal of European Consumer and Market Law 6: 257-8.

Nemeth, K., and J. Morais Carvalho. 2019. "Current Challenges for Consumer Law.” Journal of European Consumer and Market Law 3: 119-21.

Nemeth, K., and M. Scharmer. 2016. "Regulating Airbnb in Austria." Journal of European Consumer and Market Law 6: 252-3.

Smorto, G., 2008. "The Protection of the Weaker Parties in the Platform Economy." In The Cambridge Handbook of the Law of the Sharing Economy. Davidson, edited by Finck, and Infranca, 431ff. Cambridge: Cambridge University Press.

Srnicek, N. 2017. Platform Capitalism. Cambridge: Cambridge University Press.

Tomassetti, J. 2016. "Does Uber Redefine the Firm: The Postindustrial Corporation and Advanced Information Technology.” Hofstra Labor \& Employment Law Journal 34: 1-78.

Veljanovski, C. 2015. Forever Contemporary: The Economics of Ronald Coase. London: The Institute of Economic Affairs.

Wratny, J., and A. Ludera-Ruszel, Eds (2020). New Forms of Employment: Current Problems and Future Challenges. Wiesbaden: Springer. 